\title{
Notch signaling in gastrointestinal tract (Review)
}

\author{
MASUKO KATOH $^{1}$ and MASARU KATOH ${ }^{2}$ \\ ${ }^{1}$ M\&M Medical BioInformatics, Hongo 113-0033; ${ }^{2}$ Genetics and Cell Biology Section, \\ National Cancer Center Research Institute, Tokyo 104-0045, Japan \\ Received September 25, 2006; Accepted October 10, 2006
}

\begin{abstract}
Notch signaling is one of key pathways constituting the stem cell signaling network. DLL1, DLL3, DLL4, JAG1 and JAG2 with DSL domain are typical Notch ligands, while DNER, F3/Contactin and NB-3 without DSL domain are atypical Notch ligands. Notch-ligand binding to NOTCH1, $\mathrm{NOTCH} 2, \mathrm{NOTCH} 3$ or NOTCH4 receptor induces the receptor proteolysis by metalloprotease and $\gamma$-secretase to release Notch intracellular domain (NICD). Typical Notch ligands transduce signals to the CSL-NICD-Mastermind complex for the maintenance of stem or progenitor (transit-amplifying) cells through transcriptional activation of HES1, HES5, HES7, $H E Y 1, H E Y 2$ and HEYL genes, and also to the NF-kB-NICD complex for the augmentation of NF-kB signaling. Atypical Notch ligands transduce signals to the CSL-NICD-Deltex complex for the differentiation of progenitor cells through $M A G$ transcriptional activation. Notch signals are transduced to the canonical pathway (CSL-NICD-Mastermind signaling cascade) or the non-canonical pathway (NF-kB-NICD and CSL-NICD-Deltex signaling cascades) based on the expression profile of Notch ligands, Notch receptors, and Notch signaling modifiers. Canonical Notch signaling is activated in the stem or progenitor domain of gastrointestinal epithelium, such as basal layer in esophagus and lower part of the crypt in colon. Notch signaling to inhibit secretory cell differentiation is oncogenic in gastric cancer and colorectal cancer, while Notch signaling to promote keratinocyte differentiation is anti-oncogenic in esophageal squamous cell carcinoma (SCC). Single nucleotide polymorphism (SNP), epigenetic change, and genetic alteration of genes encoding Notch signaling-associated molecules will be utilized as biomarkers for gastrointestinal cancer. $\gamma$-Secretase inhibitors, functioning as Notch signaling inhibitors, will be applied as anti-cancer drugs for gastric cancer and colorectal cancer.
\end{abstract}

Correspondence to: Dr Masaru Katoh, Genetics and Cell Biology Section, National Cancer Center Research Institute, 5-1-1 Tsukiji, Chuo-ku, Tokyo 104-0045, Japan

E-mail: mkatoh-kkr@umin.ac.jp

Key words: Notch, WNT, FGF, stem cells, morphogenesis, carcinogenesis, bioinformatics, integrome network, theoretical biology

\section{Contents}

1. Overview of Notch signaling landscape

2. Notch signaling network

3. Notch signaling in normal gastrointestinal tract

4. Notch signaling in gastrointestinal cancer

5. Clinical application

\section{Overview of Notch signaling landscape}

Overview. Notch signaling pathway is implicated in selfrenewal of stem cells, cell-fate determination of progenitor cells, and terminal differentiation of proliferating cells (1-6). Notch-ligand binding induces the cleavage of Notch receptor by metalloprotease and $\gamma$-secretase to release Notch intracellular domain (NICD). Canonical Notch signaling to CSLNICD-Mastermind complex inhibits the differentiation of stem cells or progenitor (transit-amplifying) cells, while noncanonical Notch signaling to CSL-NICD-Deltex complex promotes the differentiation of progenitor cells.

Notch ligand. Delta homologs, DLL1, DLL3 and DLL4, are type I transmembrane proteins with extracellular N-terminal DSL domain and EGF-like repeats $(6,7)$. Serrate homologs, JAG1 and JAG2, are type I transmembrane proteins with extracellular N-terminal DSL domain, EGF-like repeats, cysteinerich domain and von Willebrand factor type C domain (8-10). DNER is a type I transmembrane protein with extracellular EGF-like repeats (11). F3/Contactin and NB-3 are glycosyl phosphatidylinositol (GPI)-anchored proteins with immunoglobulin-like domains and EGF-like repeats $(12,13)$. DLL1, DLL3, DLL4, JAG1 and JAG2 with DSL domain are typical Notch ligands with higher affinity, while DNER, F3/Contactin and NB-3 without DSL domain are atypical Notch ligands with lower affinity.

Notch receptor. Notch family receptors, NOTCH1, NOTCH2, NOTCH3 and NOTCH4 are type I transmembrane proteins with extracellular EGF-like repeats, Lin12/Notch repeat region, cytolasmic RAM23 domain, Ankyrin repeats and PEST domain $(14,15)$. Notch is cleaved at the S1 site by a Furinlike convertase to generate the mature heterodimeric receptor. On ligand-binding, Notch receptor is further cleaved at the S2 site by metalloprotease tumor necrosis factor- $\alpha$ converting enzyme, and at the S3 site by $\gamma$-secretase complex to give rise to NICD. Notch family receptors 


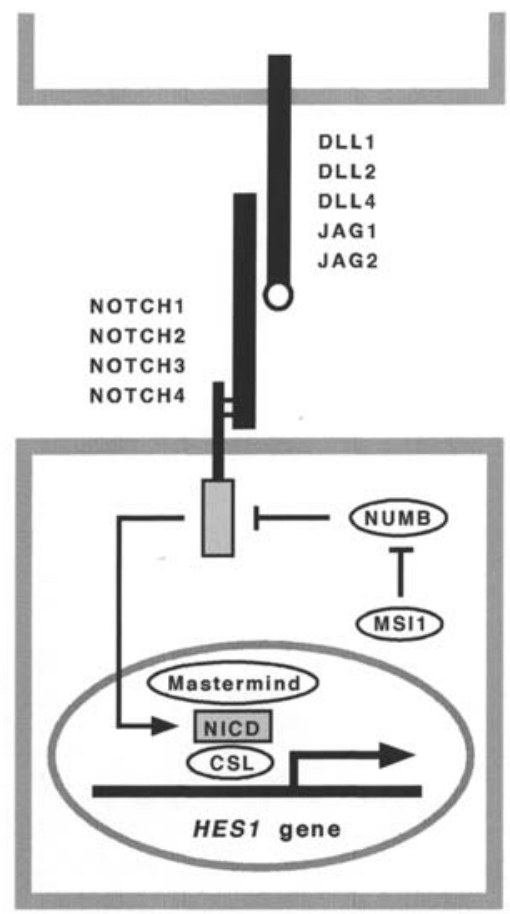

Canonical Notch Pathway

CSL - NICD - Mastermind cascade

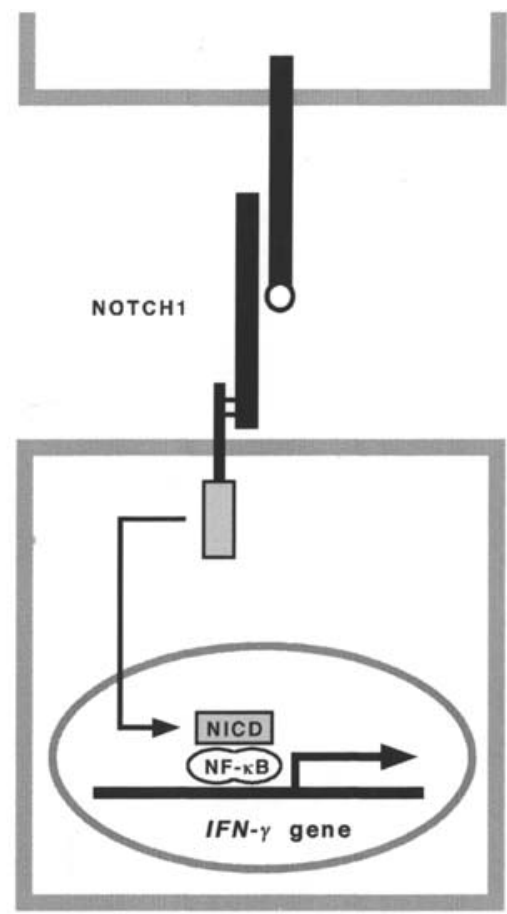

Non - canonical Notch Pathway

NF-KB - NICD cascade

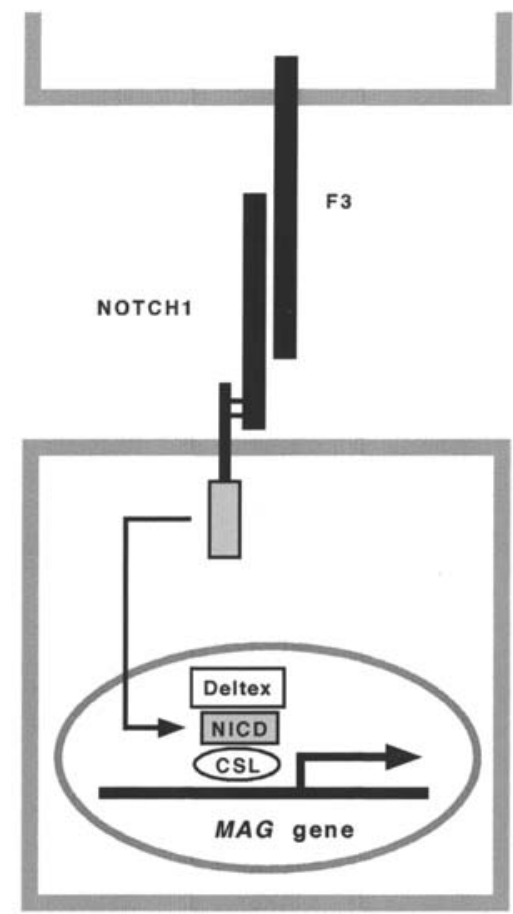

Non - canonical Notch Pathway

CSL - NICD - Deltex cascade

Figure 1. Notch signaling pathway. Notch signals are transduced to the canonical pathway (CSL-NICD-Mastermind signaling cascade) or the non-canonical pathway (NF-kB-NICD and CSL-NICD-Deltex signaling cascades) based on the expression profile of Notch ligands, Notch receptors, and Notch signaling modifiers. (Left), Binding of DLL1, DLL3, DLL4, JAG1 and JAG2 with DSL domain (open circle) to Notch receptor leads to the release of Notch intracellular domain (NICD) for transcriptional activation of Notch target genes, such as HES1, through the CSL-NICD-Mastermind complex. (Middle),

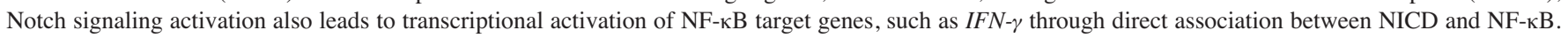
(Right), Binding of DNER, F3/Contactin and NB-3 without DSL domain to Notch receptor leads to transcriptional activation of differentiation-associated genes, such as $M A G$, through the CSL-NICD-Deltex complex.

transduce signals of DLL-type ligands, JAG-type ligands, and atypical ligands in the context-dependent manner.

Canonical Notch signaling. NICD, released after ligandbinding to Notch receptor, is translocated into the nucleus to associate with CSL (RBPSUH) transcription factor $(5,16)$. CSL-NICD complex is activated by Mastermind family coactivators MAML1, MAML2 and MAML3 (17) for transcriptional activation of HES1, HES5, HES7, HEY1, HEY2 and $H E Y L$ genes, encoding bHLH/orange domain transcriptional repressors (4,18-20). Because HES/HEY family members repress the transcription of tissue specific transcription factors, Notch signaling to the CSL-NICD-Mastermind complex results in the maintenance of stem or progenitor (transit-amplifying) cells through the inhibition of differentiation (Fig. 1, left). Signaling transduction from typical Notch ligands to the CSLNICD-Mastermind cascade is also known as the "canonical' Notch signaling pathway.

Non-canonical Notch signaling. NICD also interacts with p50 or c-Rel in the nucleus to enhance the NF- $\mathrm{BB}$ activity (21). Notch signaling to the NF-кB-NICD complex augments

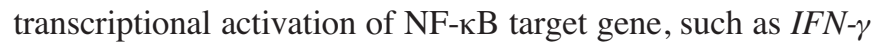
(Fig. 1, middle). On the other hand, binding of atypical Notch ligands to Notch receptor in the absence of typical Notch ligands gives rise to the association of CSL, NICD and
Deltex (11-13). Because Deltex affects the DNA-binding preferentiality of CSL, the CSL-NICD-Deltex complex activates the transcription of unique target genes, such as $M A G$ (Fig. 1, right). Because MAG is a tissue specific transcription factor to induce terminal differentiation, atypical Notch signaling to the CSL-NICD-Deltex complex results in differentiation of progenitor cells. Notch signaling to the NF$\kappa \mathrm{B}-\mathrm{NICD}$ cascade and the CSL-NICD-Deltex cascade are called the 'non-canonical' Notch signaling (Fig. 1).

Notch signaling regulator. Drosophila Neuralized and Mindbomb are RING-type E3 ubiquitin ligases inducing ubiquitination and internalization of Delta, which results in canonical Notch signaling activation in the neighboring cells $(22,23)$. NEURL1/NEURL and NEURL2 are human homologs of Drosophila Neural, while MIB1 and MIB2 are human homologs of Drosophila Mindbomb. Mouse Mib1 and Mib2 interact with Xenopus Delta, and Mib2 induces Delta ubiquitination. However, effects of human NEURL1, NEURL2, MIB1 and MIB2 on DLL-dependent Notch signaling remain to be elucidated (24). Lunatic Fringe (LFNG), Manic Fringe (MFNG) and Radical Fringe (RFNG) are Notch glycosyltransferase, which enhance Notch binding to DLL rather than JAG (25).

NUMB and NUMBL are docking proteins with phosphotyrosine-binding (PTB) domain and SH3-binding proline-rich 
A

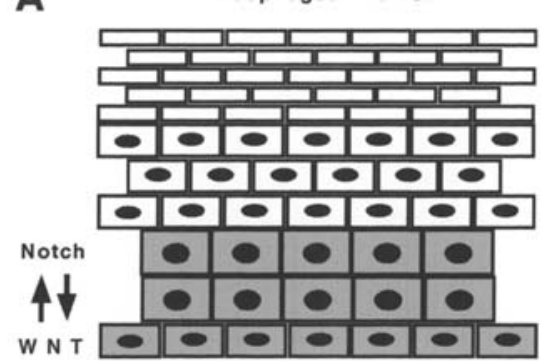

Cornified layer

Suprabasal layer

Basal layer
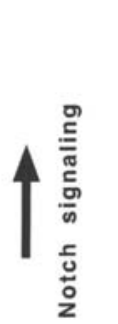

C

\begin{tabular}{|c|c|c|}
\hline \multicolumn{2}{|c|}{$\begin{array}{l}\text { Notch signaling } \\
\text { molecules }\end{array}$} & \multirow[t]{2}{*}{$\begin{array}{l}\text { Mechanisms of Notch signaling } \\
\text { activation in human cancer }\end{array}$} \\
\hline $\begin{array}{l}\text { Delta-type } \\
\text { ligand }\end{array}$ & $\begin{array}{l}\text { DLL1 } \\
\text { DLL2 } \\
\text { DLL4 }\end{array}$ & \\
\hline $\begin{array}{l}\text { Serrate-type } \\
\text { ligand }\end{array}$ & $\begin{array}{l}\text { JAG1 } \\
\text { JAG2 }\end{array}$ & Transcriptional upregulation \\
\hline $\begin{array}{l}\text { Atypical } \\
\text { ligand }\end{array}$ & $\begin{array}{l}\mathrm{F}_{3} \\
\text { NB-3 } \\
\text { DNER }\end{array}$ & \\
\hline Receptor & $\begin{array}{l}\text { NOTCH1 } \\
\text { NOTCH2 } \\
\text { NOTCH3 } \\
\text { NOTCH4 }\end{array}$ & $\begin{array}{l}\text { Chromosomal translocation } \\
\text { Gene amplification } \\
\text { Gene amplification }\end{array}$ \\
\hline $\begin{array}{l}\text { Receptor } \\
\text { modifier }\end{array}$ & $\begin{array}{l}\text { LFNG } \\
\text { MFNG } \\
\text { RFNG }\end{array}$ & \\
\hline $\begin{array}{l}\text { Positive } \\
\text { regulator }\end{array}$ & MSI1 & \\
\hline $\begin{array}{l}\text { Negative } \\
\text { regulator }\end{array}$ & $\begin{array}{l}\text { NUMB } \\
\text { NUMB }\end{array}$ & Transcriptional downregulation \\
\hline $\begin{array}{l}\text { Transcription } \\
\text { factor }\end{array}$ & RBPSUH & Interaction with viral protein \\
\hline $\begin{array}{l}\text { Transcription } \\
\text { coactivator }\end{array}$ & $\begin{array}{l}\text { MAML1 } \\
\text { MAML2 } \\
\text { MAML3 }\end{array}$ & \\
\hline $\begin{array}{l}\text { Primary } \\
\text { target }\end{array}$ & $\begin{array}{l}\text { HES1 } \\
\text { HES5 } \\
\text { HEST } \\
\text { HEY1 } \\
\text { HEY } 1 \\
\text { HEY2 } \\
\text { HEYL }\end{array}$ & \\
\hline
\end{tabular}

B

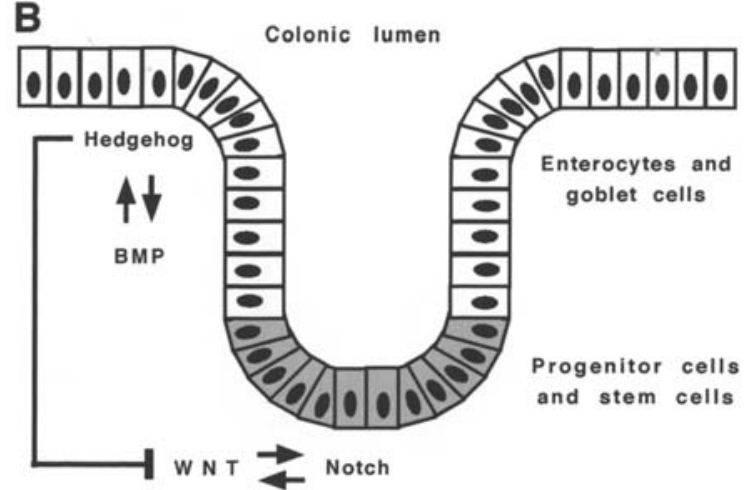

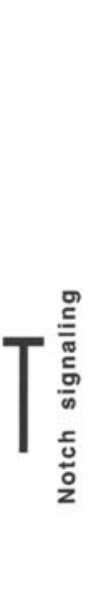

Figure 2. Notch signaling in the gastrointestinal tract and human cancer. (A), Esophagus. Notch and WNT signals are activated in the stem and progenitor cells (gray) in the basal layer. (B), Colon. Notch and WNT signals are activated in the stem and progenitor cells (gray) in the lower part of the crypt. (C), Human Notch signaling molecules and mechanisms of Notch signaling activation in human cancer. Notch signaling is aberrantly activated in a variety of human cancer due to chromosomal translocation of $N O T C H 1, N O T C H 3$, gene amplification of $N O T C H 2, N O T C H 3$, upregulation of JAG1, NOTCH1, and down-regulation of $N U M B$.

region, functioning as cytoplasmic Notch signaling inhibitors (26-28). MSI1, binding to NUMB mRNA, represses NUMB translation to activate Notch signaling (29). FBXW7/SEL10 with F-box and WD-repeats are NICD-binding protein, functioning as a component of ubiquitin ligase to degrade nuclear NICD (30).

\section{Notch signaling network}

Stem cell signaling network. Notch, WNT, FGF, Hedgehog and BMP signaling pathways constitute the stem cell signaling network regulating the balance of self-renewal, proliferation and differentiation among stem and progenitor (transitamplifying) cell population (33-42). Notch signaling plays a key role in the stem cell signaling network through the interaction with other signaling pathways. Notch signaling interaction with WNT signaling pathway will be further described.

WNT signaling pathway. WNT signals are context-dependently transduced to the canonical and non-canonical WNT signaling pathways (43-45). Canonical WNT signals are transduced through Frizzled family receptor and LRP5/LRP6 co-receptor to the $B$-catenin signaling cascade for cell-fate determination. $J A G 1$ and $N U M B$ genes are predicted as evolutionarily conserved targets of the canonical WNT signaling pathway $(10,28)$. JAG1 expressed on progenitor cells activates canonical Notch signaling pathway in the neighboring stem or progenitor cells. JAG1-dependent canonical Notch signaling pathway maintains the homeostasis of stem and progenitor cells synergistically with the canonical WNT signaling pathway.

\section{Notch signaling in normal gastrointestinal tract}

Esophagus. Esophagus is lined with stratified squamous epithelium, consisting of basal layer, suprabasal layer and cornified layer. Esophageal epithelial stem cells, located at the bottom of the basal layer, give rise to neighboring progenitor cells within the basal layer. Progenitor cells are differentiated to keratinocytes in the suprabasal layer, and then to de-nucleated cells in the cornified layer. Jag1, Jag2, Notch1 and Notch 2 are highly expressed in the basal layer of mouse esophagus, and weakly expressed in the suprabasal layer (46). JAG1, DLL1, NOTCH1, NOTCH2 and NOTCH3 are highly expressed in the basal layer of human skin epidermis, and weakly expressed in the suprabasal layer (47). Together, these facts indicate that canonical Notch signaling is activated mainly in the basal layer to maintain the balance of stem and progenitor cells (Fig. 2A).

Stomach. Fundic glands occupy fundus and body, corresponding to the proximal two thirds of the stomach. Fundic gland consists of the surface pit area with mucus cells, the isthmus/neck area with stem cells, progenitor cells and parietal cells, and the base area with parietal cells, chief cells and enteroendocrine cells. Stem cells in the isthmus/neck area give rise to progenitor cells for mucous-, parietal- and chief-cell lineage. Jag1, Jag2, Dll1, Notch1, Notch2 and Notch3 are expressed in mouse fundic mucosa (46). NOTCH1, NOTCH2, NOTCH3 and HES1 are expressed in human gastric mucosa (48).

Colon. Colon epithelium consists of a flat absorptive surface and the crypt. Stem and progenitor cells located around the 
lower part of the crypt (or proliferating crypt) give rise to enterocytes, goblet cells, and Paneth cells. Among Jag1, Jag2, Dll1, Notch1 and Notch3 expressed in colon, Jag1, Jag2 and Notchl are expressed in the lower half of the crypts (46). Canonical Notch signaling activation leads to Hes1 upregulation, and Atoh1/Hath1/Math1 down-regulation (49). Atoh1 bHLH transcription factor induces differentiation to the goblet cells. Canonical Notch signaling in colon is implicated in the maintenance of stem cells and progenitor cells, and also in the inhibition of goblet cell differentiation (Fig. 2B).

\section{Notch signaling in gastrointestinal cancer}

General view of Notch signaling in carcinogenesis. Notch signaling is aberrantly activated due to chromosomal translocation of NOTCH1 in acute lymphoblastic leukemia (14), amplification and overexpression of $\mathrm{NOTCH} 2$ in medulloblastoma (50), chromosomal translocation of NOTCH3 in lung cancer (51), amplification and overexpression of $\mathrm{NOTCH} 3$ in ovarian cancer (52), and upregulation of JAG1/NOTCH1 or down-regulation of $N U M B$ in breast cancer $(53,54)$ (Fig. 2C). Together these facts indicate that Notch signaling is oncogenic in a variety of human tumors.

On the other hand, Notch signaling is anti-oncogenic for squamous cell carcinoma (SCC) of skin and cervical uterus and also for basal cell carcinoma (BCC) of skin $(2,47,55)$, partially due to the interference with canonical WNT signaling.

Esophageal cancer. Esophageal cancer is classified into SCC, adenocarcinoma, and others. Alcohol drinking and tobacco smoking are risk factors for esophageal SCC, which is the major type of esophageal cancer in developing countries and Japan. Helicobacter pylori eradication and Barret's esophagus are risk factors for esophageal adenocarcinoma, incidence of which is gradually increasing in developed countries. Oral SCC, head and neck SCC, and esophageal SCC are similar types of cancer. Although JAG1 and RBPSUH are rarely amplified and overexpressed in oral SCC (56), JAG1 expression in head and neck SCC is significantly lower than in adjacent non-cancerous tissue (57). Canonical WNT signaling is activated in SCC, while Notch signaling is inactivated in SCC. Because Notch signaling promotes the terminal differentiation of keratinocytes (Fig. 2A), Notch signaling is anti-oncogenic in esophageal SCC.

Gastric cancer. NOTCH1, NOTCH2 and NOTCH3 were expressed in all of the eight gastric cancer cell lines, HES1 in seven gastric cancer cell lines, and ATOHI and MUC6 in three gastric cancer cell lines (48). HESI is a target gene of the canonical Notch signaling pathway, and HES1 represses transcription of ATOH1. MUC6 is a marker of chief-cell lineage. Together, these facts indicate that canonical Notch signaling pathway to inhibit chief cell differentiation is frequently activated in gastric cancer.

Colorectal cancer. NOTCH1, NOTCH2, and NOTCH3 were up-regulated in colon cancer, while $A T O H 1$ expression was down-regulated in colorectal cancer (49). Because Notch signaling inhibits the terminal differentiation of goblet cells in colorectal mucosa (Fig. 2B), Notch signaling is oncogenic in colorectal cancer.

\section{Clinical application}

Diagnostics and prognostics. High-throughput technologies and bioinformatics supervised by human intelligence is the driving force for the pharmacogenomics and pharmacogenetics in the post-genome era (58). Single nucleotide polymorphism (SNP), epigenetic change, and genetic alteration of genes encoding Notch signaling-associated molecules will be utilized as biomarkers for gastrointestinal cancer.

Preventive and therapeutics. $\gamma$-Secretase inhibitors, such as LY450139 and LY411,575, block the S3 cleavage of Notch receptors to inhibit Notch signaling activation $(59,60)$. Despite the side effects, such as thymus atrophy and intestinal goblet cell hyperplasia, $\gamma$-secretase inhibitors are promising anticancer drugs. Therefore, $\gamma$-secretase inhibitors will be applied as anti-cancer drugs for human cancer, such as gastric cancer and colorectal cancer.

\section{References}

1. Artavanis-Tsakonas S, Rand MD and Lake RJ: Notch signaling: cell fate control and signal integration in development. Science 284: 770-776, 1999

2. Radtke F and Raj K: The role of Notch in tumorigenesis: oncogene or tumor suppressor? Nat Rev Cancer 3: 765-767, 2003 .

3. Lai EC: Notch signaling: control of cell communication and cell fate. Development 131: 965-973, 2004.

4. Li JL and Harris AL: Notch signaling from tumor cells: a new mechanism of angiogenesis. Cancer Cell 8: 1-3, 2005.

5. Androutsellis-Theotokis A, Leker RR, Soldner F, et al: Notch signaling regulates stem cell numbers in vitro and in vivo. Nature 442: 823-826, 2006

6. Leong KG and Karsan A: Recent insight into the role of Notch signaling in tumorigenesis. Blood 107: 2223-2233, 2006

7. Gray GE, Mann RS, Mitsiadis E, et al: Human ligands of the Notch receptor. Am J Pathol 154: 785-794, 1999.

8. Lindsell CE, Shawber CJ, Boulter J, et al: Jagged: a mammalian ligand that activates Notch1. Cell 80: 909-917, 1995.

9. Luo B, Aster JC, Hasserjian RP, et al: Isolation and functional analysis of a cDNA for human Jagged2, a gene encoding a ligand for the Notch1 receptor. Mol Cell Biol 17: 6057-6067, 1997.

10. Katoh M and Katoh M: Notch ligand, JAG1, is evolutionarily conserved target of canonical WNT signaling pathway in progenitor cells. Int J Mol Med 17: 681-685, 2006.

11. Eiraku M, Hirata Y, Takeshima H, et al: Delta/notch-like EGFrelated receptor. J Biol Chem 277: 25400-25407, 2002.

12. Hu QD, Ang BT, Karsak M, et al: F3/contactin acts as a functional ligand for Notch during oligodendrocyte maturation. Cell 115: 163-175, 2003.

13. Cui XY, Hu QD, Tekaya M, et al: NB-3/Notch1 pathway via Deltex1 promotes neural progenitor cell differentiation into oligodendrocytes. J Biol Chem 279: 25858-25865, 2004.

14. Ellisen LW, Bird J, West DC, et al: TAN-1, the human homolog of the Drosophila notch gene, is broken by chromosomal translocations in T lymphoblastic neoplasms. Cell 66: 649-661, 1991.

15. Larsson C, Lardelli M, White I, et al: The human NOTCH1, 2, and 3 genes are located at chromosome positions 9q34, 1p13-p11, and $19 \mathrm{p} 13.2-\mathrm{p} 13.1$ in regions of neoplasia-associated translocation. Genomics 24: 253-258, 1994.

16. Matsunami N, Hamaguchi Y, Yamamoto Y, et al: A protein binding to the $\mathrm{J}_{\mathrm{K}}$ recombination sequence of immunoglobulin genes contains a sequence related to the integrase motif. Nature 342: 934-937, 1989.

17. Wu L, Sun T, Kobayashi K, et al: Identification of a family of mastermind-like transcriptional coactivators for mammalian notch receptors. Mol Cell Biol 22: 7688-7700, 2002. 
18. Iso T, Kedes L and Hamamori Y: HES and HERP families: multiple effectors of the Notch signaling pathway. J Cell Physiol 194: 237-255, 2003.

19. Katoh $\mathrm{M}$ and Katoh M: Identification and characterization of human HES2, HES3, and HES5 genes in silico. Int J Oncol 25: 529-534, 2004.

20. Katoh $\mathrm{M}$ and Katoh M: Identification and characterization of human HESL, rat Hesl and rainbow trout hesl genes in silico. Int J Mol Med 14: 747-751, 2004.

21. Shin HM, Minter LM, Cho OH, et al: Notch1 augments NF-кB activity by facilitating its nuclear retentian. EMBO J 25: 129-138, 2006.

22. Le Borgne R and Schweisguth F: Unequal segregation of Neuralized biases Notch activation during asymmetric cell division. Dev Cell 5: 139-148, 2003.

23. Itoh M, Kim CH, Palardy G, et al: Mindbomb is a ubiquitin ligase that is essential for efficient activation of Notch signaling by Delta. Dev Cell 4: 67-82, 2003.

24. Koo BK, Yoon KJ, Yoo KW, et al: Mind bomb-2 is an E3 ligase for Notch ligand. J Biol Chem 280: 22335-22342, 2005.

25. Johnston SH, Rauskolb C, Wilson R, et al: A family of mammalian Fringe genes implicated in boundary determination and the Notch pathway. Development 124: 2245-2254, 1997.

26. Sherrington R, Rogaev EI, Liang Y, et al: Cloning of a gene bearing missense mutations in early-onset familial Alzheimer's disease. Nature 375: 754-760, 1995.

27. Wong WT, Schumacher C, Salcini AE, et al: A protein-binding domain, EH, identified in the receptor tyrosine kinase substrate Eps 15 and conserved in evolution. Proc Natl Acad Sci USA 92: 9530-9534, 1995

28. Katoh M and Katoh M: NUMB is a break of WNT-Notch signaling cycle. Int J Mol Med 18: 517-521, 2006.

29. Good P, Yoda A, Sakakibara S, et al: The human Musashi homolog 1 (MSI1) gene encoding the homologue of Musashi/ Nrp-1. Genomics 52: 382-384, 1998.

30. Gupta-Rossi N, Le Bail O, Gonen $\mathrm{H}$, et al: Functional interaction between SEL-10, an F-box protein, and the nuclear form of activated Notch1 receptor. J Biol Chem 276: 34371-34378, 2001.

31. Katoh M: WNT and FGF gene clusters. Int J Oncol 21: 1269-1273, 2002.

32. Heller RS, Klein T, Ling Z, Heimberg H, Katoh M, Madsen OD and Serup P: Expression of WNT, Frizzled, sFRP, and DKK genes in adult human pancreas. Gene Expr 11: 141-147, 2003.

33. Garciadiego-Cazares D, Rosales C, Katoh M and ChimalMonroy J: Coordination of chondrocyte differentiation and joint formation by $\alpha 5 \beta 1$ integrin in the developing appendicular skeleton. Development 131: 4735-4742, 2004.

34. Van den Brink GR, Bleuming SA, Hardwick JC, et al: Indian Hedgehog is an antagonist of Wnt signaling in colonic epithelial cell differentiation. Nat Genet 36: 277-282, 2004.

35. Katoh $\mathrm{M}$ and Katoh M: Comparative genomics on FGF8, FGF17, and FGF18 orthologs. Int J Mol Med 16: 493-496, 2005.

36. Katoh $\mathrm{M}$ and Katoh M: Comparative genomics on FGF20 orthologs. Oncol Rep 14: 287-290, 2005.

37. Katoh $\mathrm{Y}$ and Katoh M: Hedgehog signaling in gastric cancer. Cancer Biol Ther 4: 1050-1054, 2005.

38. Radtke F, Clevers $\mathrm{H}$ and Riccio O: From gut homoestasis to cancer. Curr Mol Med 6: 275-289, 2006.

39. Katoh Y and Katoh M: WNT antagonist, SFRP1, is Hedgehog signaling target. Int J Mol Med 17: 171-175, 2006.

40. Katoh Y and Katoh M: Comparative genomics on HHIP family orthologs. Int J Mol Med 17: 391-395, 2006.
41. Katoh Y and Katoh M: FGF signaling inhibitor, SPRY4, is evolutionarily conserved target of WNT signaling pathway in progenitor cells. Int J Mol Med 17: 529-532, 2006.

42. Katoh M and Katoh M: Cross-talk of WNT and FGF signaling pathways at GSK3B to regulate $\beta$-catenin and SNAIL signaling cascades. Cancer Biol Ther 5: 1059-1064, 2006.

43. Katoh M: WNT2B: comparative integromics and clinical application. Int J Mol Med 16: 1103-1108, 2005.

44. Katoh M: Epithelial-mesenchymal transition in gastric cancer. Int J Oncol 27: 1677-1683, 2005.

45. Swain RK, Katoh M, Medina A and Steinbeisser H: Xenopus frizzled-4S, a splicing variant of Xfz4, is a context-dependent activator and inhibitor of Wnt/B-catenin signaling. Cell Commun Signal 3: 12, 2005.

46. Sander GR and Powell BC: Expression of notch receptors and ligands in the adult gut. J Histochem Cytochem 52: 509-516, 2004.

47. Thelu J, Rossio P and Favier B: Notch signaling is linked to epidermal cell differentiation level in basal cell carcinoma, psoriasis and wound healing. BMC Dermatol 2: 7, 2002.

48. Sekine A, Akiyama Y, Yanagihara K, et al: Hath1 up-regulates gastric mucin gene expression in gastric cells. Biochem Biophys Res Commun 344: 1166-1171, 2006.

49. Leow CC, Romero MS, Ross S, et al: Hath1, down-regulated in colon adenocarcinomas, inhibits proliferation and tumorigenesis of colon cancer cells. Cancer Res 64: 6050-6057, 2004.

50. Fan X, Mikolaenko I, Elhassan I, et al: Notch1 and Notch2 have opposite effects on embryonal brain tumors. Cancer Res 64: 7787-7793, 2004.

51. Dang TP, Gazdar AF, Virmani AK, et al: Chromosome 19 translocation, overexpression of Notch3, and human lung cancer. J Natl Cancer Inst 92: 1355-1357, 2000.

52. Park JT, Li M, Nakayama K, et al: Notch3 gene amplification in ovarian cancer. Cancer Res 66: 6312-6318, 2006.

53. Reedijk M, Odorcic S, Chang L, et al: High-level coexpression of JAG1 and NOTCH1 is observed in human breast cancer and is associated with poor overall survival. Cancer Res 65: 8530-8537, 2005.

54. Pece S, Serresi M, Santolini E, et al: Loss of negative regulation by Numb over Notch is relevant to human breast carcinogenesis. J Cell Biol 167: 215-221, 2004.

55. Proweller A, Tu L, Lepore JJ, et al: Impaired Notch signaling promotes de novo squamous cell carcinoma formation. Cancer Res 66: 7438-7444, 2006

56. Snijders AM, Schmidt BL, Fridlyand J, et al: Rare amplicons implicate frequent deregulation of cell fate specification pathways in oral squamous cell carcinoma. Oncogene 24: 4232-4242, 2005 .

57. Leethanakul C, Patel V, Gillespie J, et al: Distinct pattern of expression of differentiation and growth-related genes in squamous cell carcinomas of the head and neck revealed by the use of laser capture microdissection and cDNA arrays. Oncogene 19: 3220-3224, 2000.

58. Katoh M: Bioinformatics for cancer management in the postgenome era. Technol Cancer Res Treat 5: 169-176, 2006.

59. Siemers ER, Quinn JF, Kaye J, et al: Effects of a $\gamma$-secretase inhibitor in a randomized study of patients with Alzheimer disease. Neurology 66: 602-604, 2006.

60. Hyde LA, McHugh NA, Chen J, et al: Studies to investigate the in vivo therapeutic window of the $\gamma$-secretase inhibitor LY411, 575 in the CRND8 mouse. J Pharmacol Exp Ther (Epub ahead of print). 